AperTO - Archivio Istituzionale Open Access dell'Università di Torino

\title{
Matrix metalloproteinases and vascular endothelial growth factor expression in canine leukaemias
}

\section{This is the author's manuscript}

Original Citation:

\section{Availability:}

This version is available http://hdl.handle.net/2318/125903

since 2016-10-04T23:48:43Z

Published version:

DOI:10.1016/j.tvjl.2012.10.004

Terms of use:

Open Access

Anyone can freely access the full text of works made available as "Open Access". Works made available under a Creative Commons license can be used according to the terms and conditions of said license. Use of all other works requires consent of the right holder (author or publisher) if not exempted from copyright protection by the applicable law. 


\section{(3) \\ UNIVERSITÀ DEGLI STUDI DI TORINO}

This Accepted Author Manuscript (AAM) is copyrighted and published by Elsevier. It is posted here by agreement between Elsevier and the University of Turin. Changes resulting from the publishing process - such as editing, corrections, structural formatting, and other quality control mechanisms may not be reflected in this version of the text. The definitive version of the text was subsequently published in Matrix metalloproteinases and vascular endothelial growth factor expression in canine leukaemias The Veterinary Journal, Volume 196, Issue 2, May 2013, Pages 260-262. http://dx.doi.org/10.1016/j.tvj1.2012.10.004

You may download, copy and otherwise use the AAM for non-commercial purposes provided that your license is limited by the following restrictions:

(1) You may use this AAM for non-commercial purposes only under the terms of the CC-BY-NC-ND license.

(2) The integrity of the work and identification of the author, copyright owner, and publisher must be preserved in any copy.

(3) You must attribute this AAM in the following format: Creative Commons BY-NC-ND license (http://creativecommons.org/licenses/by-nc-nd/4.0/deed.en), http://www.sciencedirect.com/science/article/pii/S1090023312004261 
Matrix metalloproteinases and vascular endothelial growth factor expression in canine leukaemias

\author{
Arianna Aricò a , Mery Giantin ${ }^{\mathrm{a}}$, Mariaelena Gelain ${ }^{\mathrm{a}}$, Fulvio Riondato ${ }^{\mathrm{c}}$, Michele Mortarino ${ }^{\mathrm{b}}$, \\ Stefano Comazzi ${ }^{\text {b }}$, Mauro Dacasto ${ }^{\text {a }}$, Massimo Castagnaro ${ }^{\text {a }}$, Luca Aresu ${ }^{\text {a,* }}$ \\ ${ }^{a}$ Department of Comparative Biomedicine and Food Science, University of Padova, Viale dell'Università 16, 35020 Agripolis \\ Legnaro (PD), Italy \\ ${ }^{b}$ Department of Animal Pathology, Public Health and Veterinary Hygiene, Faculty of Veterinary Medicine, University of \\ Milano, Via Celoria 10, 20133 Milano, Italy ${ }^{c}$ Department of Animal Pathology, Faculty of Veterinary Medicine, University of \\ Torino, Via Leonardo da Vinci 44, 10095 Grugliasco (TO), Italy
}

*Corresponding author. Tel.: +39 049 8272963. E-mail address: luca.aresu@unipd.it (L. Aresu).

Despite their different biological behaviour, canine acute leukaemia (AL) and chronic lymphocytic leukaemia (CLL) are both characterized by an abnormal cellular proliferation, replacing normal bone marrow tissue and subsequently invading different organs and blood (Adam et al., 2009). Matrix metalloproteinases (MMPs) are involved in the proteolytic degradation of extracellular matrix (ECM). Tumour cells can secrete MMPs to promote invasion and metastatic spread (Giantin et al., 2012), as well as tissue inhibitors of metalloproteinases (TIMPs), which control the proteolytic activity of MMPs. MT1MMP mediates the activation of pro-MMP-2 (Egeblad and Werb, 2002). RECK, an endogenous MMP inhibitor, down-regulates MMP-2, MMP-9 and MT1-MMP (Takagi et al., 2005). Vascular endothelial growth factor (VEGF) is one of the most potent angiogenic promoters (Takahashi and Shibuya, 2005).

The present study assessed the expression profiles of the MMP-2, MMP-9, MT1-MMP, TIMP-1, TIMP2, RECK, VEGF-A and VEGF-164 transcripts and the protein levels of MMP-2, MMP-9 and VEGF-A in canine leukaemias.

Clinical, clinicopathological and immunophenotypic data were obtained by complete blood cell count with leukocyte differential count and flow cytometric analysis and were used to classify leukaemia samples (Gelain et al., 2010). Blood samples from six healthy dogs matched according to age, breed and gender served as control for immunocytochemistry and extracted lymphocytes for quantitative real-time RT-PCR (qRT-PCR). Target gene expression was evaluated as previously described (Giantin et al., 2012). The concentration of each set of primers was optimised to efficiently amplify its target (see Table 1 of Supplementary material, Appendix A). Data were expressed as relative quantification values if the target gene was undetectable or not quantifiable in control lymphocytes (CTRL), while as fold changes if the target gene was quantifiable in CTRL.

Protein expression levels of MMP-2, MMP-9, and VEGF-A were evaluated by immunocytochemistry. The intensity (0-3) and the percentage of immunoassayed tumour cells were assessed for each antibody in ten randomly selected fields at 400 magnification. The total score for each examined field was obtained by multiplying the intensity score by the percentage. A final ratio was obtained after averaging the ten selected fields (Giantin et al., 2012). Statistical analysis was performed by using the Mann-Whitney test and the Kruskal-Wallis test followed by Dunn's post-test for qRT-PCR and immunocytochemistry data. A nonparametric Spearman correlation analysis was used to determine the different correlations. Statistical significance was set at $\mathrm{P}<0.05$.

Eleven female dogs with AL were included. All dogs showed anaemia, thrombocytopenia and leucocytosis; median age was 8 years (range, 2-12 years). Two dogs were diagnosed with T-acute 
lymphoblastic leukaemia (ALL) (CD34+CD5+), 2 with B-ALL (CD34+CD79a+) and 7 with acute undifferentiated leukaemia (CD34+CD45+). Twelve dogs were diagnosed with T-CLL: 8 CD8+, 1 CD4+, 1 CD21+ and 2 CD4 CD8. There were 10 males and 2 females; median age was 10 years (range, 5-13 years). All dogs showed leukocytosis; six of them were anaemic. The median percentage values (range) of blasts in blood were $98.1 \%(72-100 \%)$ and $88.2 \%(72-96 \%)$ of the total nucleated cells for AL and CLL, respectively.

Concerning qRT-PCR (Tables 1 and 2), TIMP-2 and MT1-MMP mRNA levels were significantly higher in AL than CLL. In CLL, significant positive correlations were found between MMP-9 and VEGF mRNAs $(\mathrm{P}<0.01$; Spearman $\mathrm{r}=0.75)$ and between MMP-9 and TIMP-1 mRNAs $(\mathrm{P}<0.05$, Spearman $\mathrm{r}=0.62)$. Negative correlations were found between the percentage of neoplastic cells in CLL and MMP-9 mRNA (P $<0.01$; Spearman $\mathrm{r}=0.74)$, VEGF mRNA $(\mathrm{P}<0.05$; Spearman $\mathrm{r}=0.59)$, TIMP-1 mRNA $(\mathrm{P}<0.05$, Spearman $r=0.62)$ and TIMP-2 mRNA $(\mathrm{P}<0.05$, Spearman $r=0.65)$. The percentage of blasts was negatively correlated with MMP-9 mRNA in AL $(\mathrm{P}<0.05$; Spearman $r=0.70)$. Concerning immunocytochemical analysis (Table 3), a significant difference was observed between the control peripheral blood and the leukaemia blood samples for VEGF, MMP-9 and MMP-2 (Figs. 1 a,b,c and 2 a,b,c).

Angiogenesis and invasion play an essential role in haematopoietic tumours in people (Moehler et al., 2003). Several molecules, in particular MMPs, TIMPs and VEGF, regulate invasion and dissemination of neoplastic cells. In our study, MMP-9 mRNA was not quantifiable and the protein was not expressed in control lymphocytes; whereas higher MMP-9 transcript and protein levels were present in CLL compared to AL. In this contest, leukaemic cells might express and activate MMP-9 for transendothelial migration and basement membrane invasion.

VEGF was over-expressed at the mRNA and protein level in both AL and CLL with respect to controls; furthermore, their protein values were higher in CLL compared to AL. We hypothesise that VEGF in leukaemic cells could stimulate new blood vessels growth, and subsequently increase endothelium permeability and cell motility leading to systemic dissemination (Letilovic et al., 2006). We also demonstrated a significant positive correlation between VEGF and MMP-9 mRNA levels in CLL samples. VEGF may stimulate MMP-9 secretion by acting as an autocrine factor, and subsequently MMP-9 may release different angiogenic factors that bind to ECM in a sort of vicious circle.

AL and CLL over-expressed TIMP-1 transcript; this data might confirm the role of TIMP-1 as stimulating growth factor secreted by neoplastic cells. A significant positive correlation was also demonstrated in CLL between MMP-9 and TIMP-1. This is not surprising because MMP-9 is frequently found to be coexpressed in neoplastic cells together with TIMP-1. MT1-MMP transcript was significantly higher in AL than CLL, supporting its aggressive behaviour. MT1-MMP is crucial for cancer cell growth and tissue invasion (Hotary et al., 2003). The inverse correlation between blasts percentage and mRNA data may be explained by the influence of residual normal leukocytes in the expression of these genes.

Limitations of this study include the small population size, the use of immunocytochemistry to quantify protein expression, and the limited value of mRNA in investigating MMPs, which are regulated at different levels. Currently, synthetic MMP inhibitors have demonstrated efficacy in various models of tumour metastasis and invasion, thereby showing the role of MMPs as therapeutic target. Further studies are warranted to test their antitumoural efficacy in dogs with leukaemia.

\section{Conflict of interest statement}

None of the authors has any financial or personal relationships that could inappropriately influence or bias the content of the paper. This study was approved by the Institutional Review Board of Padua University Veterinary School (PRIN 2008). All samples were collected with consent of the owners. 
Appendix A. Supplementary material

Supplementary data associated with this article can be found, in the online version

\section{References}

Adam, F., Villiers, E., Watson, S., Coyne, K., Blackwood, L., 2009. Clinical pathological and epidemiological assessment of morphologically and immunologically confirmed canine leukaemia. Veterinary Comparative Oncology 3, 181-195.

Egeblad, M., Werb, Z., 2002. New functions for the matrix metalloproteinases in cancer progression. Nature Reviews Cancer 2, 161-174.

Gelain, M.E., Rossi, G., Giori, L., Comazzi, S., Paltrinieri, S., 2010. Identification of neoplastic cells in blood using the Sysmex XT-2000iV: A preliminary step in the diagnosis of canine leukemia. Veterinary Clinical Pathology 39, 169-179.

Giantin, M., Aresu, L., Benali, S., Aricò, A., Morello, E.M., Martano, M., Vascellari, M., Castagnaro, M., Lopparelli, R.M., Zancanella, V., Granato, A., Mutinelli, F., Dacasto, M., 2012. Expression of matrix metalloproteinases, tissue inhibitors of metalloproteinases and vascular endothelial growth factor in canine mast cell tumours. Journal of Comparative Pathology (Epub ahead of print).

Hotary, K.B., Allen, E.D., Brooks, P.C., Datta, N.S., Long, M.W., Weiss, S.J., 2003. Membrane type I matrix metalloproteinase usurps tumor growth control imposed by the three-dimensional extracellular matrix. Cell 114, 33-45.

Letilovic, T., Vrhovac, R., Verstovsek, S., Jaksic, B., Ferrajoli, A., 2006. Role of angiogenesis in chronic lymphocytic leukemia. Cancer 107, 925-934.

Moehler, T.M., Ho, A.D., Goldschmidt, H., Barlogie, B., 2003. Angiogenesis in hematologic malignancies. Critical Reviews in Oncology/Hematology 45, 227- 244.

Takagi, S., Kato, Y., Asano, K., Ohsaki, T., Bosnakovski, D., Hoshino, Y., Okumura, M., Kadosawa, T., Fujinaga, T., 2005. Matrix metalloproteinase inhibitor RECK expression in canine tumors. Journal of Veterinary Medical Science 67, 761- 767.

Takahashi, H., Shibuya, M., 2005. The vascular endothelial growth factor (VEGF)/ VEGF receptor system and its role under physiological and pathological conditions. Clinical Science (London) 108, 227-241. 
Table 1

MMP-9, MMP-2, TIMP-2 and RECK mRNA expression in AL and CLL blood samples.

\begin{tabular}{llll}
\hline Target genes & AL & CLL & P \\
\hline MMP-9 & $0.20 \pm 0.19$ & $0.59 \pm 0.64$ & 0.1891 \\
MMP-2 & n.d. & n.d. & - \\
TIMP-2 & $5.28 \pm 3.94$ & $0.51 \pm 0.60$ & 0.0043 \\
RECK & $0.11 \pm 0.12$ & $0.23 \pm 0.19$ & 0.1611 \\
\hline
\end{tabular}

Quantitative real time RT-PCR data are expressed in arbitrary units (mean \pm SD) as relative quantification values (RQ). Mann-Whitney test.

Target gene expression was not quantifiable in control lymphocytes. n.d. $=$ not detectable.

$\mathrm{AL}=$ acute leukaemias.

$\mathrm{CLL}=$ chronic lymphocytic leukaemia.

Table 2

MT1-MMP, TIMP-1, VEGF-A and VEGF-164 mRNA expression in AL and CLL blood samples.

\begin{tabular}{llll}
\hline Target genes & $\mathrm{AL}$ & $\mathrm{CLL}$ & $\mathrm{P}$ \\
\hline MT1-MMP & $1.20 \pm 0.91$ & $0.36 \pm 0.48$ & 0.0316 \\
TIMP-1 & $0.39 \pm 0.25$ & $0.77 \pm 0.72$ & 0.2485 \\
VEGF-A & $2.55 \pm 3.17$ & $3.19 \pm 3.57$ & 0.8777 \\
VEGF-164 & $4.10 \pm 5.05$ & $4.07 \pm 4.75$ & 0.7818 \\
\hline
\end{tabular}

Quantitative real-time RT-PCR data are expressed in arbitrary units (mean \pm SD) as fold changes vs. control lymphocytes. Mann-Whitney test.

A fold change equal to 1 was assumed for control lymphocytes. $\mathrm{AL}=$ acute leukaemia.

$\mathrm{CLL}=$ chronic lymphocytic leukaemia.

Table 3

Immunostaining score values for MMP-9, MMP-2 and VEGF-A expressed as the mean (range).

\begin{tabular}{|c|c|c|c|c|}
\hline & Control peripheral blood & $\mathrm{AL}$ & CLL & $P$ \\
\hline MMP-9 & $0.66 \pm 0.51$ & $78.11 \pm 64.48$ & $104.1 \pm 36.8$ & 0.0009 \\
\hline MMP-2 & $0.16 \pm 0.40$ & $56 \pm 53.5$ & $71.73 \pm 35.51$ & 0.0008 \\
\hline VEGF-A & $0.5 \pm 0.54$ & $21.33 \pm 23.62$ & $27.9 \pm 15.62$ & 0.0008 \\
\hline
\end{tabular}

Results are expressed as products of intensity and index of immunoassayed tumor cells (0-300). MannWhitney test.

$\mathrm{AL}=$ acute leukaemia.

$\mathrm{CLL}=$ chronic lymphocytic leukaemia. 


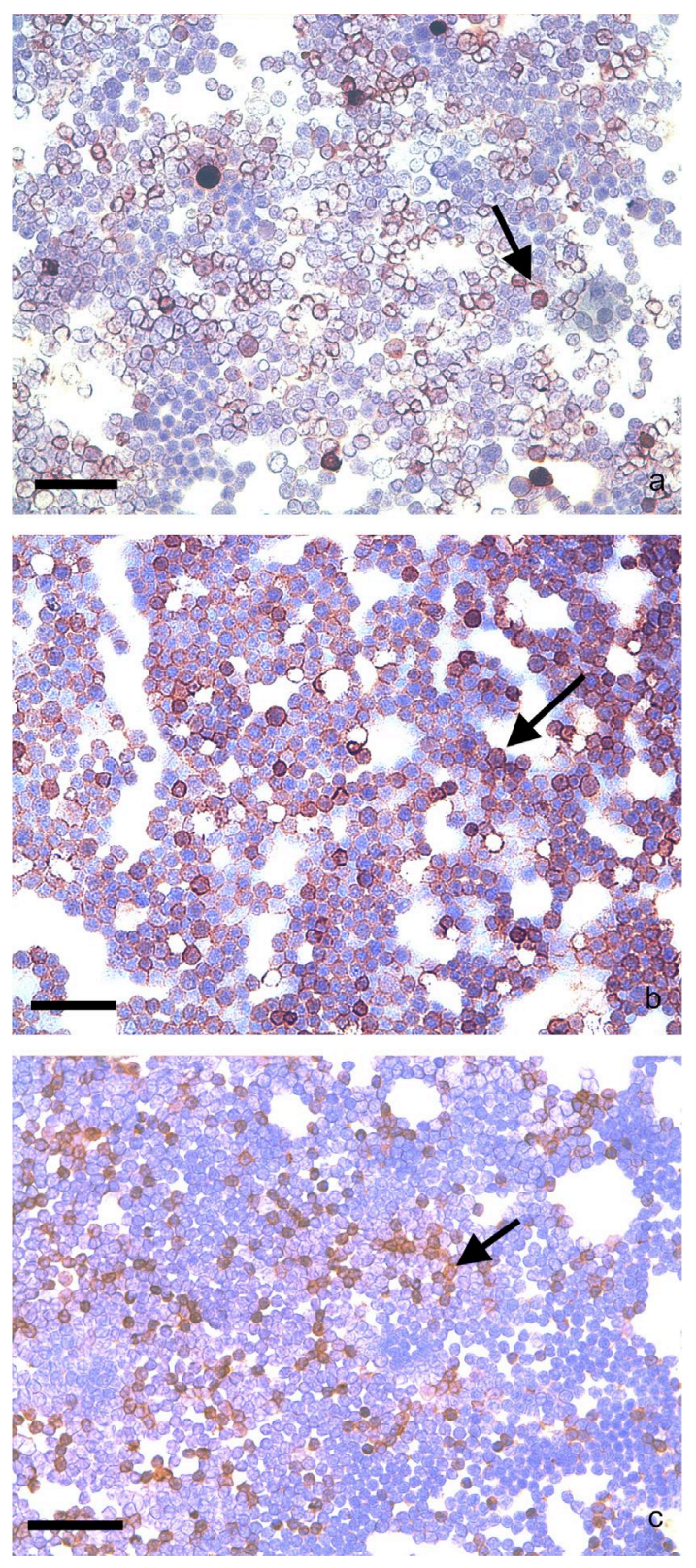

Fig. 1. ALL. Peripheral blood. (a) plasma cells and lymphoid leukaemia cells brown immunostained for MMP-2 (arrow); (b) lymphoid leukaemia cells intensely immunostained for MMP-9 (arrow); and (c) VEGF (arrow). Immunocytochemistry, (bar $=70 \mathrm{~lm})$. 


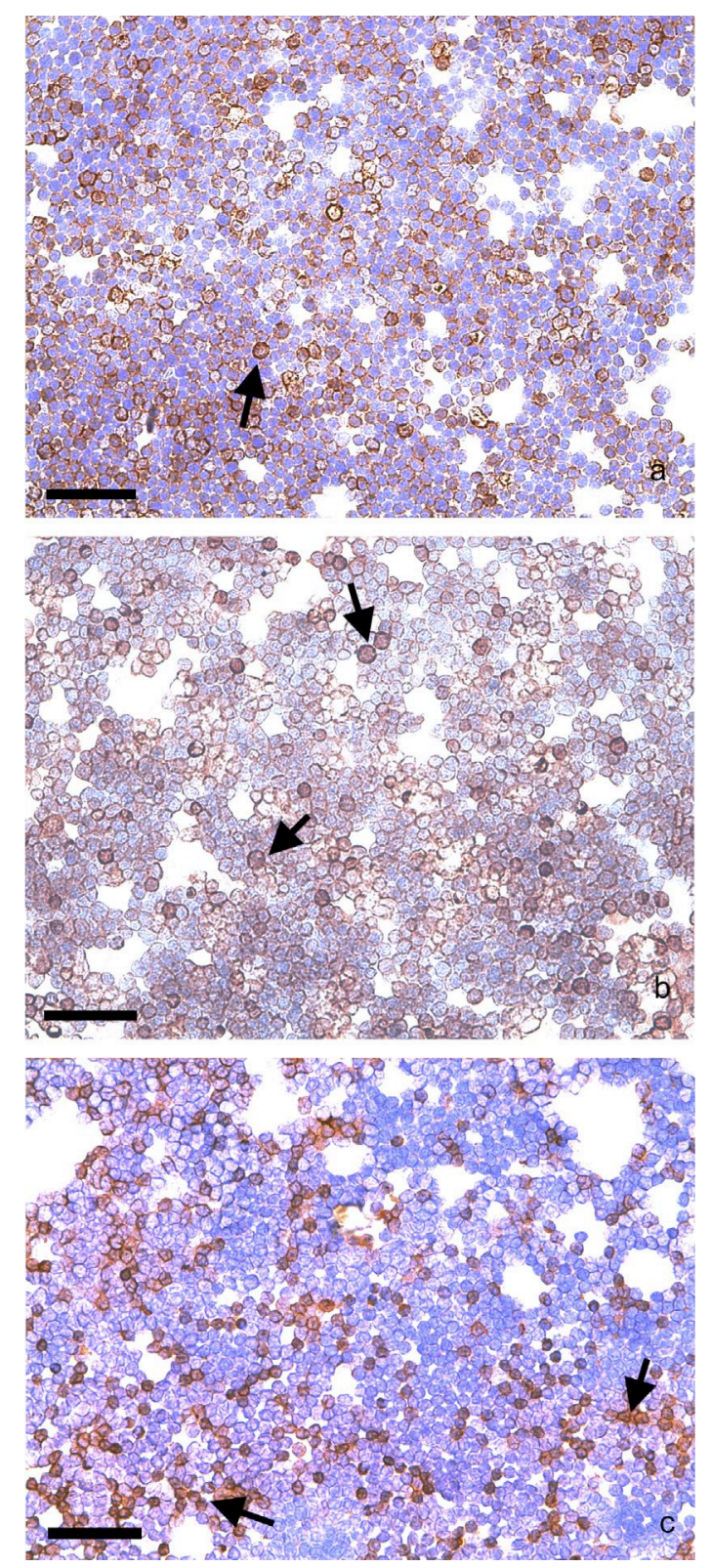

Fig. 2. CLL. Peripheral blood. lymphoid leukaemia cells intensely and diffusely brown immunostained for (a) MMP-2 (arrow), (b) MMP-9 (arrow), and (c) VEGF (arrow). Immunocytochemistry, (bar = $70 \mathrm{~lm}$ ). 